\title{
Hospital utilization rates following antipsychotic dose reduction in mood disorders: implications for treatment of tardive dyskinesia
}

\author{
Stanley N. Caroff ${ }^{*}$ D, Fan Mu², Rajeev Ayyagari ${ }^{2}$, Traci Schilling ${ }^{3}$, Victor Abler ${ }^{3}$ and Benjamin Carroll ${ }^{3}$
}

\begin{abstract}
Background: The relative benefits and risks of long-term maintenance treatment with antipsychotics have not been well studied in patients with bipolar disorder and major depressive disorder. For example, while antipsychotic dose reduction has been recommended in the management of serious side effects associated with antipsychotics, there is limited evidence on the impact of lowering doses on the course of underlying mood disorders.

Methods: This retrospective cohort study analyzed the impact of antipsychotic dose reduction in patients with bipolar disorder or major depressive disorder. Medical claims from six US states over a 6-year period were analyzed for patients with $\geq 10 \%$ or $\geq 30 \%$ reductions in antipsychotic dose (cases) and compared using survival analyses with matched controls receiving a stable dosage. Outcomes included hospitalizations for disease-specific mood disorders, other psychiatric disorders and all-cause emergency room visits, and claims for tardive dyskinesia.

Results: A total of 23,992 patients with bipolar disorder and 17,766 with major depressive disorder had a $\geq 10 \%$ dose reduction, while 19,308 and 14,728, respectively, had a $\geq 30 \%$ dose reduction. In multivariate analyses, cases with $a \geq 10 \%$ dose reduction had a significantly increased risk of disease-specific admission (bipolar disorder: hazard ratio [95\% confidence interval], 1.22 [1.15-1.31]; major depressive disorder: 1.22 [1.11-1.34]), other psychiatric admission (bipolar disorder: 1.19 [1.13-1.24]; major depressive disorder: 1.17 [1.11-1.23]), all-cause admission (bipolar disorder: 1.17 [1.12-1.23]; major depressive disorder: 1.11 [1.05-1.16]), and all-cause emergency room visits (bipolar disorder: 1.09 [1.05-1.13]; major depressive disorder: 1.07 [1.02-1.11]) (all $P<0.01$ ). Similar results were observed following an $\geq 30 \%$ dose reduction. Dose reduction was not associated with decreased claims for tardive dyskinesia.

Conclusions: Patients with mood disorders who had antipsychotic dose reductions showed small but statistically significant increases in all-cause and mental health-related hospitalizations, which may lead to increased healthcare costs. These results highlight the need for additional long-term studies of the necessity and safety of maintenance antipsychotic treatment in mood disorders.
\end{abstract}

Keywords: Tardive dyskinesia, Antipsychotic medication, Bipolar disorder, Major depressive disorder, Relapse, Healthcare burden

\footnotetext{
* Correspondence: Caroffs@pennmedicine.upenn.edu

'Department of Psychiatry, Corporal Michael J. Crescenz VA Medical Center

and the Perelman School of Medicine at the University of Pennsylvania,

3900 Woodland Avenue, Philadelphia, PA 19104, USA

Full list of author information is available at the end of the article
}

C C The Author(s). 2020 Open Access This article is licensed under a Creative Commons Attribution 4.0 International License, which permits use, sharing, adaptation, distribution and reproduction in any medium or format, as long as you give appropriate credit to the original author(s) and the source, provide a link to the Creative Commons licence, and indicate if changes were made. The images or other third party material in this article are included in the article's Creative Commons licence, unless indicated otherwise in a credit line to the material. If material is not included in the article's Creative Commons licence and your intended use is not permitted by statutory regulation or exceeds the permitted use, you will need to obtain permission directly from the copyright holder. To view a copy of this licence, visit http://creativecommons.org/licenses/by/4.0/ The Creative Commons Public Domain Dedication waiver (http://creativecommons.org/publicdomain/zero/1.0/) applies to the data made available in this article, unless otherwise stated in a credit line to the data. 


\section{Background}

Bipolar disorder (BD) and major depressive disorder (MDD) have an estimated annual prevalence of 2.8 and $6.7 \%$, respectively $[1,2]$. Significant advances have been achieved in treating these disorders with a broad range of mood stabilizers, antidepressants, and electroconvulsive treatments. Several antipsychotics have also recently received approval for treatment of BD and MDD [3-12]. Although MDD is more prevalent in the population, antipsychotics are particularly effective and commonly started during the acute phase of mania in BD [13]. Despite the fact that evidence on the long-term effectiveness and safety of antipsychotics in these episodic and remitting disorders is limited, many patients remain on antipsychotics chronically and perhaps unnecessarily $[3,11$, 12, 14-17].

Prolonged use of antipsychotics is associated with serious side effects, including tardive dyskinesia (TD) as one example [4-10]. Historically, patients with mood disorders were considered at high risk for TD when treated with first-generation antipsychotics (FGAs), although this is confounded by age, gender, and intermittent treatment, all of which are known risk factors for TD $[10,11]$. By comparison, there are limited data on TD risk in patients with mood disorders receiving longterm treatment with second-generation antipsychotics (SGAs); although it appears to be diminished, the risk of TD remains clinically significant $[11,12,18]$.

When side effects emerge during maintenance treatment with antipsychotics, management options include drug maintenance, discontinuation, switching, or dose reduction [5, 6, 12, 19-23]. For example, in patients with mood disorders in remission, maintenance treatment with antipsychotics may be unnecessary, and discontinuation may be reasonable to facilitate remission of TD or other side effects. In patients who require continued antipsychotic maintenance treatment, dose reduction has also been considered as an option once TD occurs. In a previous retrospective cohort study, we demonstrated that antipsychotic dose reductions resulted in significant increases in both all-cause and mental health-related hospitalizations, worsening the overall healthcare burden in schizophrenia patients [23]. However, there are no data examining the effect of dose reduction on symptoms of TD in mood disorders [20, 24, 25]. Even more important for clinical decision making, there is no evidence on the impact of antipsychotic dose reduction on the course of illness in patients with BD or MDD $[14,26]$.

To further address the gap in knowledge on the risks of dose reduction as a recommended treatment intervention for side effects of antipsychotic treatment, including TD, we used the same methodology from the previous study in schizophrenia [23] to conduct a retrospective matched cohort study to analyze the utilization of hospital-based resources resulting from $\geq 10 \%$ and $\geq 30 \%$ reductions in antipsychotic doses for patients with $\mathrm{BD}$ or MDD.

\section{Methods \\ Study objective and data sources}

This retrospective matched cohort study compared the risk of all-cause and mental health-related inpatient admissions and emergency room (ER) visits for patients with mood disorders who received a stable dose versus those who had a dose reduction of oral antipsychotic monotherapy. The methods used, which are briefly summarized here, were described in detail in a previous study of schizophrenia [23]. Identical selection and outcome criteria, procedures, and statistical analyses were employed, except in this study, the target population was patients with mood disorders.

This study used de-identified claims data from the most recent 6 years for 26.6 million Medicaid-eligible beneficiaries from Iowa, Kansas, Missouri, New Jersey, Mississippi, and Wisconsin from 2008 to 2017. The database complies with the privacy rules of the Health Insurance Portability and Accountability Act. This study was reviewed by the New England Independent Review Board on August 31, 2017 and granted an exemption from consent requirements.

\section{Patient selection}

Eligible patients met the following inclusion criteria: $\geq 18$ years of age on the index date; $\geq 1$ diagnosis of $\mathrm{BD}$ or MDD in the most recent 6 years of data for each state; $\geq 2$ fills of an oral antipsychotic prescription after the first BD or MDD diagnosis; $\geq 1$ antipsychotic monotherapy treatment period that was $\geq 90$ days with a stable oral dosage; and a baseline period of $\geq 6$ months of continuous enrollment prior to the index date. Diagnoses were determined by ICD-9 and ICD-10 (International Classification of Diseases) codes recorded in the database.

Patients were excluded if they lived in New Jersey and turned 65 years of age after 2012 because they were eligibility for both Medicare and Medicaid, or if they received more than one oral antipsychotic concurrently.

Patients within the BD and MDD groups were identified as cases or controls based on whether they had a $\geq 10 \%$ antipsychotic dose reduction. Cases were defined as patients who had a stable dosage of oral antipsychotic monotherapy for $\geq 90$ days and then experienced $a \geq 10 \%$ dose reduction from the stable dose. Controls, matched on age, sex, type or health plan, state, index drug (FGA or SGA), and index year, included patients who were on a stable dosage of monotherapy with a duration of $\geq 91$ days and did not experience $\mathrm{a} \geq 10 \%$ dose reduction. A subset of cases from the BD and MDD groups (and their matched controls) who had a dose reduction of $\geq 30 \%$ 
were selected for subgroup analyses. The $\geq 10 \%$ reduction was chosen to capture clinically significant but minor dose reductions, and $\geq 30 \%$ reduction was chosen as a moderate dose change for comparison. The full distribution of dose reductions by percentiles for selected drugs is listed in Additional file 4.

The index date was defined as the date of the initial dose reduction for cases and the first prescription fill after the first 90 days of a stable dose period for controls. The index drug was the oral antipsychotic being used on the index date. Patients were followed until 2 years after the index date, dose escalation, treatment switch/ addition, an outcome event, or end of eligibility, whichever came first (study period).

\section{Study measures and outcomes}

Patients were assessed during the baseline period or on the index date for demographics, index year, index drug, psychiatric comorbidity profile, Charlson Comorbidity Index (CCI), psychotherapy, psychiatric medication, and observed disease duration, defined as the first observed $\mathrm{BD}$ or MDD diagnosis date prior to the index date. The mean durations of follow-up were also reported.

The primary outcome measure of the study was allcause inpatient admission and ER visits as well as admissions for disease-specific BD, MDD, or for other psychiatric diagnoses (for ICD-9 and ICD-10 codes see Additional file 1). For each analysis in which admissions associated with other listed psychiatric conditions were evaluated, admissions associated with disease-specific $\mathrm{BD}$ or MDD were excluded. We also took advantage of the opportunity to conduct a secondary exploratory analysis, by examining claims for TD (ICD-9 code of 333.85 and ICD-10 code of G24.0) including: (1) all patients with TD claims regardless of claims during the baseline period, (2) patients without TD claims during the baseline period, and (3) patients with TD claims during the baseline period who had at least one additional TD claim during the first year.

\section{Statistical analyses}

Patient characteristics were compared between cases and controls using Wilcoxon signed-ranked tests for continuous variables and McNemar's tests for categorical variables. Kaplan-Meier analyses with logrank tests were used to estimate the median time to each outcome of interest between cases and controls. Univariable and multivariable Cox proportional hazard models were used to compare outcomes and the multivariable models adjusted for age (continuous), disease duration, CCI score, psychiatric comorbidity profile, psychotherapy use, and use of psychiatric medication. All variables evaluated at baseline were adjusted in the multivariable model for comprehensiveness, except for the variables matched or those which may cause collinearity. Hazard ratios (HRs) and corresponding 95\% confidence intervals (CIs) were reported for the Cox proportional hazard models.

\section{Results \\ Baseline characteristics}

In the BD group, 23,992 patients were included in the $\geq 10 \%$ dose-reduction cohort and paired with an equal number of controls (Fig. 1). There were 19,308 patients who had $\mathrm{a} \geq 30 \%$ antipsychotic dose reduction. For cases who experienced $\geq 10 \%$ dose reductions and their matched controls, the mean age was 41.0 years, $37.8 \%$ were men, and 42.7 and $20.1 \%$ had fee-for-service (FFS) and health maintenance organization (HMO) insurance plans, respectively (Table 1 ). The mean $\mathrm{BD}$ disease duration was significantly longer for cases (26.0 months) vs. controls (18.8 months), and the mean duration of follow-up was significantly longer for controls (6.5 months) vs. cases (4.0 months; both $P<0.001)$. Controls had significantly higher rates of substance use disorders, anxiety disorders, MDD, and other depressive disorders (all $P<0.001$ ). Cases had higher rates of claims for schizophrenia than controls $(P<0.001)$. TD was present in $0.1 \%$ of both cases and controls. The CCI was similar for cases and controls $(P=0.64)$.

In the MDD group, 17,766 patients were included in the $>10 \%$ dose-reduction cohort and paired with an equal number of controls. There were 14,728 patients who had $\mathrm{a} \geq 30 \%$ antipsychotic dose reduction (Fig. 1). For MDD cases who experienced $\geq 10 \%$ dose reductions and their matched controls, the mean age was 44.2 years, $33.5 \%$ were men, and 42.3 and $18.1 \%$ had FFS and HMO insurance, respectively (Table 1). The mean disease duration was significantly longer for MDD cases (25.2 months) vs. controls (18.0 months), and the mean duration of follow-up was significantly longer for MDD controls (6.4 months) vs. cases ( 4.2 months; both $P<0.001$ ) Controls had significantly higher rates of substance use disorders, anxiety disorders, and depressive disorders other than MDD (both $P<0.001$ ) compared with cases. Conversely, cases had significantly higher rates of claims for $\mathrm{BD}$, personality disorders, and schizophrenia (all $P<0.001)$ than controls. TD was present in $0.1 \%$ of both cases and controls. The CCI was similar for MDD cases and controls $(P=0.26)$. Patient characteristics among patients with $\mathrm{a} \geq 30 \%$ dose reduction were similar to patients with $\mathrm{a} \geq 10 \%$ dose reduction in both $\mathrm{BD}$ and MDD groups (Additional file 2).

\section{Dosing patterns}

The most commonly used antipsychotic drugs among $\mathrm{BD}$ and MDD cases and controls were similar 


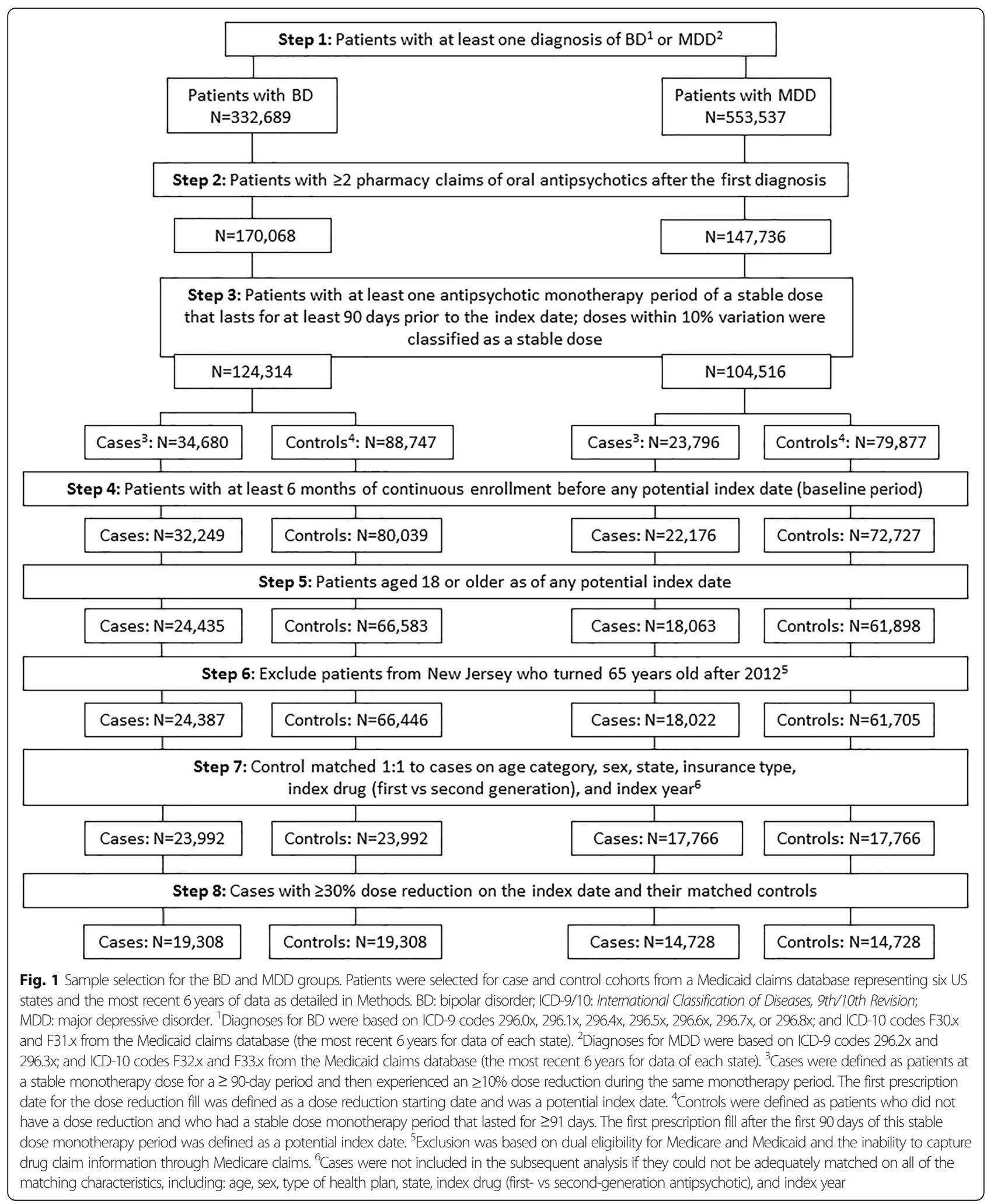

(Additional file 3). The mean dosages of all antipsychotic medications at the index date were higher among cases than controls in both diagnostic groups. Across all antipsychotic medications, $25 \%$ of patients had a dose reduction of approximately $33 \%$ on the index date, and approximately half of patients had a dose reduction of 
Table 1 Baseline Characteristics of Patients With $\geq 10 \%$ Antipsychotic Dose Reduction in the BD and MDD Groups

\begin{tabular}{|c|c|c|c|c|c|c|}
\hline \multirow[t]{3}{*}{ Demographics } & \multicolumn{3}{|l|}{$\mathrm{BD}$} & \multicolumn{3}{|l|}{ MDD } \\
\hline & \multirow{2}{*}{$\begin{array}{l}\text { Case } \\
N=23,992\end{array}$} & \multirow{2}{*}{$\begin{array}{l}\text { Control } \\
N=23,992\end{array}$} & \multirow[t]{2}{*}{$P$-value } & \multirow{2}{*}{$\begin{array}{l}\text { Case } \\
N=17,766\end{array}$} & \multirow{2}{*}{$\begin{array}{l}\text { Control } \\
N=17,766\end{array}$} & \multirow[t]{2}{*}{$P$-value } \\
\hline & & & & & & \\
\hline Age, mean $\pm S D$, years & $41.00 \pm 13.83$ & $41.01 \pm 13.82$ & 0.27 & $44.18 \pm 14.15$ & $44.17 \pm 14.14$ & 0.51 \\
\hline Men, n (\%) & $9076(37.83 \%)$ & $9076(37.83 \%)$ & - & $5958(33.54 \%)$ & $5958(33.54 \%)$ & - \\
\hline State, n (\%) & & & - & & & - \\
\hline lowa & $1831(7.63 \%)$ & $1831(7.63 \%)$ & & $863(4.86 \%)$ & $863(4.86 \%)$ & \\
\hline Kansas & $1808(7.54 \%)$ & $1808(7.54 \%)$ & & $1243(7.00 \%)$ & $1243(7.00 \%)$ & \\
\hline Mississippi & 1432 (5.97\%) & $1432(5.97 \%)$ & & $1243(7.00 \%)$ & $1243(7.00 \%)$ & \\
\hline Missouri & $10,297(42.92 \%)$ & $10,297(42.92 \%)$ & & $8796(49.51 \%)$ & 8796 (49.51\%) & \\
\hline New Jersey & $5594(23.32 \%)$ & $5594(23.32 \%)$ & & 3805 (21.42\%) & 3805 (21.42\%) & \\
\hline Wisconsin & $3030(12.63 \%)$ & $3030(12.63 \%)$ & & $1816(10.22 \%)$ & $1816(10.22 \%)$ & \\
\hline Insurance type, $n$ (\%) & & & - & & & - \\
\hline FFS & $10,255(42.74 \%)$ & $10,255(42.74 \%)$ & & $7513(42.29 \%)$ & 7513 (42.29\%) & \\
\hline $\mathrm{HMO}$ & 4817 (20.08\%) & $4817(20.08 \%)$ & & $3219(18.12 \%)$ & $3219(18.12 \%)$ & \\
\hline Mixed & $8920(37.18 \%)$ & $8920(37.18 \%)$ & & 7034 (39.59\%) & 7034 (39.59\%) & \\
\hline Disease duration, mean $\pm \mathrm{SD}$, months & $26.00 \pm 17.49$ & $18.80 \pm 16.65$ & $<0.001^{*}$ & $25.15 \pm 17.22$ & $18.00 \pm 16.08$ & $<0.001^{*}$ \\
\hline Duration of follow-up, mean $\pm S D$, months & $3.94 \pm 6.53$ & $6.46 \pm 9.19$ & $<0.001^{*}$ & $4.21 \pm 6.77$ & $6.37 \pm 8.83$ & $<0.001^{*}$ \\
\hline \multicolumn{7}{|l|}{ Index characteristics, $n$ (\%) } \\
\hline Index Year & & & - & & & - \\
\hline 2008 & 349 (1.45\%) & $349(1.45 \%)$ & & $233(1.31 \%)$ & $233(1.31 \%)$ & \\
\hline 2009 & $1342(5.59 \%)$ & $1342(5.59 \%)$ & & $790(4.45 \%)$ & $790(4.45 \%)$ & \\
\hline 2010 & $1908(7.95 \%)$ & 1908 (7.95\%) & & $1254(7.06 \%)$ & $1254(7.06 \%)$ & \\
\hline 2011 & $2967(12.37 \%)$ & $2967(12.37 \%)$ & & $1860(10.47 \%)$ & $1860(10.47 \%)$ & \\
\hline 2012 & $4014(16.73 \%)$ & $4014(16.73 \%)$ & & $2803(15.78 \%)$ & $2803(15.78 \%)$ & \\
\hline 2013 & $4203(17.52 \%)$ & $4203(17.52 \%)$ & & $3077(17.32 \%)$ & $3077(17.32 \%)$ & \\
\hline 2014 & 2877 (11.99\%) & 2877 (11.99\%) & & $2148(12.09 \%)$ & $2148(12.09 \%)$ & \\
\hline 2015 & $3157(13.16 \%)$ & $3157(13.16 \%)$ & & $2447(13.77 \%)$ & $2447(13.77 \%)$ & \\
\hline 2016 & $2618(10.91 \%)$ & $2618(10.91 \%)$ & & $2545(14.33 \%)$ & $2545(14.33 \%)$ & \\
\hline 2017 & $557(2.32 \%)$ & $557(2.32 \%)$ & & $609(3.43 \%)$ & $609(3.43 \%)$ & \\
\hline Index Drug Class & & & - & & & - \\
\hline First-generation antipsychotic & $1421(5.92 \%)$ & $1421(5.92 \%)$ & & $1032(5.81 \%)$ & $1032(5.81 \%)$ & \\
\hline Second-generation antipsychotic & $22,571(94.08 \%)$ & $22,571(94.08 \%)$ & & $16,734(94.19 \%)$ & $16,734(94.19 \%)$ & \\
\hline $\mathrm{CCl}$, mean $\pm \mathrm{SD}$ & $0.61 \pm 1.19$ & $0.60 \pm 1.17$ & 0.64 & $0.76 \pm 1.32$ & $0.74 \pm 1.33$ & 0.26 \\
\hline \multicolumn{7}{|l|}{ Psychiatric comorbidities, $n$ (\%) } \\
\hline Substance-related and addictive disorders & $6539(27.25 \%)$ & $6952(28.98 \%)$ & $<0.001^{*}$ & $4706(26.49 \%)$ & 4865 (27.38\%) & 0.05 \\
\hline Anxiety disorders & $5630(23.47 \%)$ & $6129(25.55 \%)$ & $<0.001^{*}$ & $4879(27.46 \%)$ & $5351(30.12 \%)$ & $<0.001^{*}$ \\
\hline $\mathrm{BD}$ & - & - & - & $5190(29.21 \%)$ & $4654(26.20 \%)$ & $<0.001^{*}$ \\
\hline Bipolar-related disorders (excluding BD) & $210(0.88 \%)$ & $226(0.94 \%)$ & 0.47 & $178(1.00 \%)$ & $192(1.08 \%)$ & 0.50 \\
\hline MDD & $4505(18.78 \%)$ & $5081(21.18 \%)$ & $<0.001^{*}$ & - & - & - \\
\hline Depressive disorders (excluding MDD) & $4429(18.46 \%)$ & $4950(20.63 \%)$ & $<0.001^{*}$ & $4226(23.79 \%)$ & $4678(26.33 \%)$ & $<0.001^{*}$ \\
\hline Personality disorders & $1322(5.51 \%)$ & $1234(5.14 \%)$ & 0.08 & $1025(5.77 \%)$ & $884(4.98 \%)$ & $<0.001^{*}$ \\
\hline Schizophrenia & $5783(24.10 \%)$ & $5139(21.42 \%)$ & $<0.001^{*}$ & $3819(21.50 \%)$ & $3108(17.49 \%)$ & $<0.001^{*}$ \\
\hline Schizophrenia spectrum disorders & $1961(8.17 \%)$ & $1952(8.14 \%)$ & 0.89 & $1576(8.87 \%)$ & 1517 (8.54\%) & 0.27 \\
\hline Sleep-wake disorders & 2395 (9.98\%) & $2453(10.22 \%)$ & 0.38 & 2044 (11.51\%) & 2142 (12.06\%) & 0.11 \\
\hline
\end{tabular}


Table 1 Baseline Characteristics of Patients With $\geq 10 \%$ Antipsychotic Dose Reduction in the BD and MDD Groups (Continued)

\begin{tabular}{|c|c|c|c|c|c|c|}
\hline \multirow[t]{3}{*}{ Demographics } & \multicolumn{3}{|l|}{$\underline{\mathrm{BD}}$} & \multicolumn{3}{|l|}{ MDD } \\
\hline & \multirow{2}{*}{$\begin{array}{l}\text { Case } \\
\mathrm{N}=23,992\end{array}$} & \multirow{2}{*}{$\begin{array}{l}\text { Control } \\
N=23,992\end{array}$} & \multirow[t]{2}{*}{$P$-value } & \multirow{2}{*}{$\begin{array}{l}\text { Case } \\
N=17,766\end{array}$} & \multirow{2}{*}{$\begin{array}{l}\text { Control } \\
N=17,766\end{array}$} & \multirow[t]{2}{*}{$P$-value } \\
\hline & & & & & & \\
\hline Trauma- and stressor-related disorders & $2939(12.25 \%)$ & $2985(12.44 \%)$ & 0.52 & $2559(14.40 \%)$ & $2636(14.84 \%)$ & 0.24 \\
\hline Tardive dyskinesia & $18(0.08 \%)$ & $26(0.11 \%)$ & 0.29 & $19(0.11 \%)$ & $17(0.10 \%)$ & 0.87 \\
\hline \multicolumn{7}{|l|}{ Non-psychiatric comorbidities, $n$ (\%) } \\
\hline AIDS/HIV & $277(1.15 \%)$ & $280(1.17 \%)$ & 0.93 & $242(1.36 \%)$ & $259(1.46 \%)$ & 0.47 \\
\hline Cancer & $412(1.72 \%)$ & $463(1.93 \%)$ & 0.09 & $416(2.34 \%)$ & $444(2.50 \%)$ & 0.35 \\
\hline Cerebrovascular disease & $809(3.37 \%)$ & $744(3.10 \%)$ & 0.09 & $881(4.96 \%)$ & $812(4.57 \%)$ & 0.08 \\
\hline Congestive heart failure & $729(3.04 \%)$ & $689(2.87 \%)$ & 0.28 & $734(4.13 \%)$ & $773(4.35 \%)$ & 0.31 \\
\hline Chronic pulmonary disease & $5305(22.11 \%)$ & $5309(22.13 \%)$ & 0.97 & $4362(24.55 \%)$ & $4240(23.87 \%)$ & 0.13 \\
\hline Dementia & $352(1.47 \%)$ & $275(1.15 \%)$ & $<0.01^{*}$ & $456(2.57 \%)$ & $357(2.01 \%)$ & $<0.001^{*}$ \\
\hline Diabetes with chronic complication & $816(3.40 \%)$ & $792(3.30 \%)$ & 0.55 & $800(4.50 \%)$ & $787(4.43 \%)$ & 0.76 \\
\hline Diabetes without chronic complication & $3259(13.58 \%)$ & 2985 (12.44\%) & $<0.001^{*}$ & $2741(15.43 \%)$ & $2590(14.58 \%)$ & $<0.05^{*}$ \\
\hline Hemiplegia or paraplegia & $289(1.20 \%)$ & $236(0.98 \%)$ & $<0.05^{*}$ & $291(1.64 \%)$ & $243(1.37 \%)$ & $<0.05^{*}$ \\
\hline Mild liver disease & $1125(4.69 \%)$ & $1106(4.61 \%)$ & 0.69 & $954(5.37 \%)$ & $934(5.26 \%)$ & 0.65 \\
\hline Metastatic solid tumor & $60(0.25 \%)$ & 79 (0.33\%) & 0.13 & $70(0.39 \%)$ & $83(0.47 \%)$ & 0.32 \\
\hline Myocardial infarction & $230(0.96 \%)$ & $242(1.01 \%)$ & 0.61 & $195(1.10 \%)$ & $205(1.15 \%)$ & 0.65 \\
\hline Moderate or severe liver disease & $87(0.36 \%)$ & $77(0.32 \%)$ & 0.48 & $76(0.43 \%)$ & $76(0.43 \%)$ & 1.00 \\
\hline Peptic ulcer disease & $157(0.65 \%)$ & $170(0.71 \%)$ & 0.51 & $147(0.83 \%)$ & $144(0.81 \%)$ & 0.91 \\
\hline Peripheral vascular disease & $811(3.38 \%)$ & $666(2.78 \%)$ & $<0.001^{*}$ & $767(4.32 \%)$ & $716(4.03 \%)$ & 0.17 \\
\hline Renal disease & $545(2.27 \%)$ & $497(2.07 \%)$ & 0.14 & $520(2.93 \%)$ & $490(2.76 \%)$ & 0.35 \\
\hline Rheumatic disease & $336(1.40 \%)$ & $333(1.39 \%)$ & 0.94 & $352(1.98 \%)$ & $374(2.11 \%)$ & 0.43 \\
\hline \multicolumn{7}{|l|}{ Psychotherapy, $n$ (\%) } \\
\hline Psychoanalysis & $1(0.00 \%)$ & $2(0.01 \%)$ & 1.00 & $0(0.00 \%)$ & $0(0.00 \%)$ & - \\
\hline Psychotherapy in crisis & $46(0.19 \%)$ & $44(0.18 \%)$ & 0.92 & $42(0.24 \%)$ & $39(0.22 \%)$ & 0.82 \\
\hline Psychotherapy non-crisis & $3806(15.86 \%)$ & $4039(16.83 \%)$ & $<0.01^{*}$ & 3249 (18.29\%) & $3463(19.49 \%)$ & $<0.01^{*}$ \\
\hline \multicolumn{7}{|l|}{ Psychiatric medication, $n$ (\%) } \\
\hline Antidepressant & $13,490(56.23 \%)$ & $13,776(57.42 \%)$ & $<0.001^{*}$ & $11,906(67.02 \%)$ & $12,036(67.75 \%)$ & $<0.05^{*}$ \\
\hline Anticholinergic & 2649 (11.04\%) & $2043(8.52 \%)$ & $<0.001^{*}$ & $1736(9.77 \%)$ & 1232 (6.93\%) & $<0.001^{*}$ \\
\hline Sedative & 3494 (14.56\%) & 3473 (14.48\%) & 0.47 & 2906 (16.36\%) & 2878 (16.20\%) & 0.68 \\
\hline Mood stabilizer & 10,302 (42.94\%) & 9507 (39.63\%) & $<0.001^{*}$ & $6574(37.00 \%)$ & 6171 (34.73\%) & $<0.001^{*}$ \\
\hline Anxiety medication & 8015 (33.41\%) & 8446 (35.20\%) & $<0.001^{*}$ & 6607 (37.19\%) & $6869(38.66 \%)$ & $<0.01^{*}$ \\
\hline ADHD medication & $2053(8.56 \%)$ & 1995 (8.32\%) & 0.31 & $1100(6.19 \%)$ & 1106 (6.23\%) & 0.91 \\
\hline
\end{tabular}

$A D H D$ attention deficit hyperactivity disorder, $A I D S / H I V$ acquired immune deficiency syndrome/human immunodeficiency virus infection, $B D$ bipolar disorder, $C C I$ Charlson Comorbidity Index, FFS fee-for-service, HMO health maintenance organization, MDD major depressive disorder, $S D$ standard deviation. ${ }^{*} P<0.05$

$50 \%$ or less; the mean dose reductions ranged from $45.1 \%$ (ziprasidone; MDD group) to $56.6 \%$ (paliperidone; BD group) (Additional file 4).

\section{Hospital utilization outcomes}

$\mathrm{BD}$ cases with $\mathrm{a} \geq 10 \%$ dose reduction had a higher rate of a BD-related admission compared to controls $(P<0.001$; Fig. 2). The first-year event rate for BDrelated admission was $19.2 \%$ for cases and $15.9 \%$ for controls, a difference of $3.3 \%$. The adjusted HR was 1.22 (95\% CI: 1.15, 1.31; $P<0.001$; Table 2). The first-year event rate of psychiatric admissions for other disorders was $36.0 \%$ for cases and $32.1 \%$ for controls, a difference of 3.9\% $(P<0.001$; Additional file 5). The adjusted HR was 1.19 (95\% CI: 1.13, 1.24; $P<0.001$; Table 2).

BD cases had a higher all-cause inpatient admission event rate $(36.3 \%)$ than their matched controls $(32.7 \%$; Additional file 6) with an adjusted HR of 1.17 (95\% CI: 1.12, 1.23; $P<0.001$; Table 2). BD cases had a higher first-year ER visit event rate (52.1\%) than matched controls (49.9\%; Additional file 7) with an adjusted HR of 1.09 (95\% CI: 1.05, 1.13, $P<0.001$; Table 2). Results 


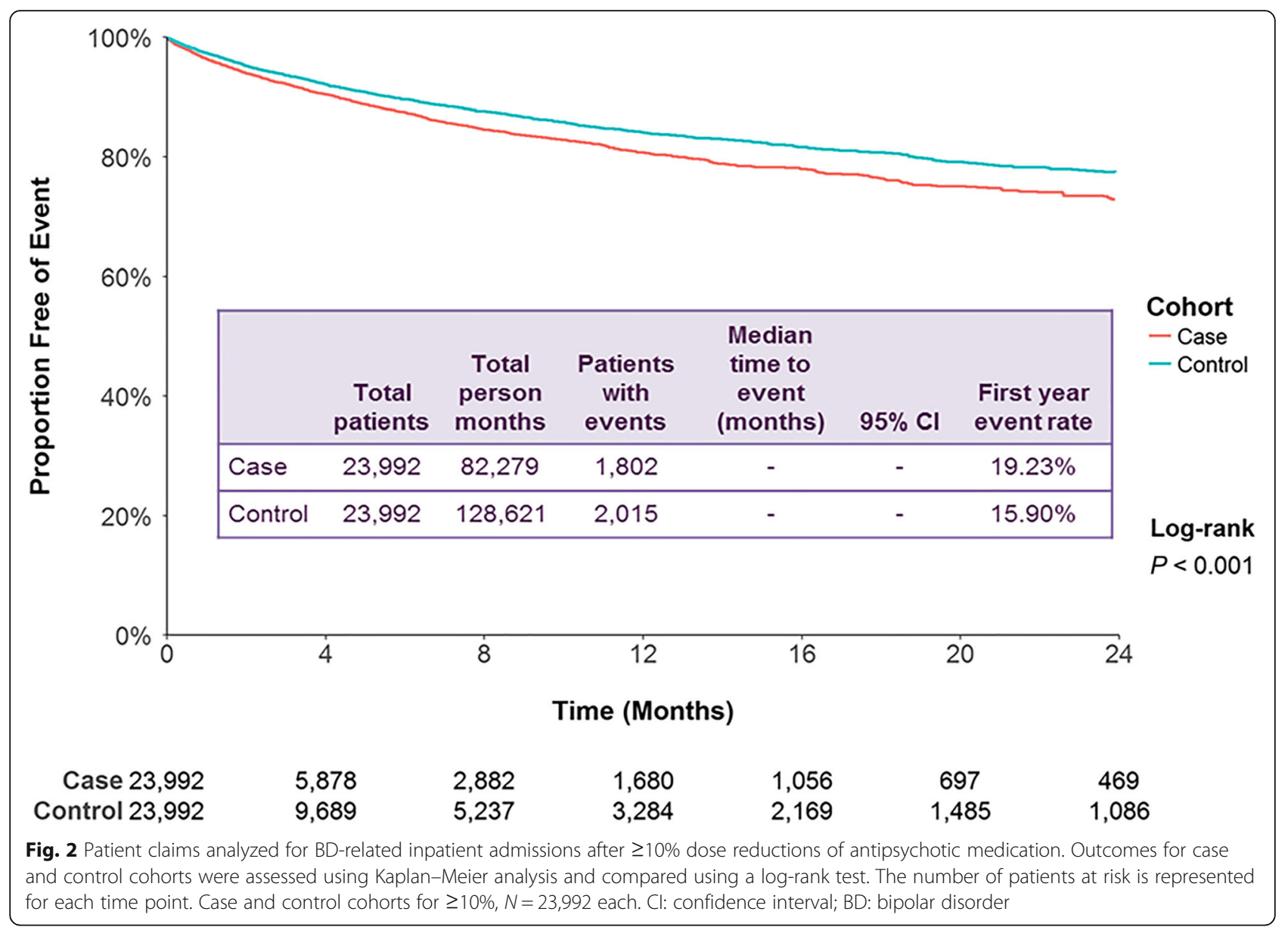

were similar for $\mathrm{BD}$ cases with $\mathrm{a} \geq 30 \%$ dose reduction vs. controls.

MDD cases with $a \geq 10 \%$ dose reduction had a higher rate of an MDD-related admission compared to controls $(P<0.001$; Fig. 3). The first-year event rate for MDDrelated admission was $11.8 \%$ for cases and $10.1 \%$ for controls, a difference of $1.7 \%$. The adjusted HR was 1.22 (95\% CI: 1.11, 1.34; $P<0.001$; Table 2). MDD cases (32.5\%) had a higher rate of psychiatric admissions for other disorders compared to controls $(30.1 \% ; P<0.001$; Additional file 8) with an adjusted HR of 1.17 (95\% CI: 1.11, 1.23, $P<0.001$; Table 2).

MDD cases had a higher all-cause inpatient admission event rate (37.6\%) than their matched controls (35.7\%; Additional file 9). The adjusted HR was 1.11 (95\% CI: 1.05, 1.16; $P<0.001$; Table 2). MDD cases also had a higher first-year ER visit event rate (51.1\%) than matched controls (50.2\%; Additional file 10). The

Table 2 Comparisons of Inpatient and Emergency Room Admissions and TD Claims Among Patients With $\geq 10 \%$ or $\geq 30 \%$ Antipsychotic Dose Reductions vs Controls in the BD and MDD Groups

\begin{tabular}{|c|c|c|c|c|c|c|c|c|}
\hline & \multicolumn{8}{|c|}{ Adjusted HR (95\% Cl) } \\
\hline & \multicolumn{4}{|l|}{$\mathrm{BD}$} & \multicolumn{3}{|l|}{ MDD } & \multirow[b]{2}{*}{$P$} \\
\hline & $\geq 10 \%$ & $P$ & $\geq 30 \%$ & $P$ & $\geq 10 \%$ & $P$ & $\geq 30 \%$ & \\
\hline Disease-specific admission & $1.22(1.15,1.31)$ & $<0.001^{*}$ & $1.24(1.15,1.33)$ & $<0.001^{*}$ & $1.22(1.11,1.34)$ & $<0.001^{*}$ & $1.27(1.14,1.41)$ & $<0.001^{*}$ \\
\hline Psychiatric admission & $1.19(1.13,1.24)$ & $<0.001^{*}$ & $1.19(1.13,1.25)$ & $<0.001^{*}$ & $1.17(1.11,1.23)$ & $<0.001^{*}$ & $1.16(1.10,1.24)$ & $<0.001^{*}$ \\
\hline All-cause IP admission & $1.17(1.12,1.23)$ & $<0.001^{*}$ & $1.17(1.11,1.24)$ & $<0.001^{*}$ & $1.11(1.05,1.16)$ & $<0.001^{*}$ & $1.12(1.06,1.18)$ & $<0.001^{*}$ \\
\hline All-cause ER visit & $1.09(1.05,1.13)$ & $<0.001^{*}$ & $1.10(1.06,1.15)$ & $<0.001^{*}$ & $1.07(1.02,1.11)$ & $<0.01^{*}$ & $1.08(1.03,1.13)$ & $<0.01^{*}$ \\
\hline TD claim for all patients & $1.45(0.75,2.82)$ & 0.27 & $1.83(0.87,3.88)$ & 0.11 & $2.40(1.19,4.83)$ & $0.01^{*}$ & $2.51(1.14,5.52)$ & $0.02^{*}$ \\
\hline TD claim for patients without baseline TD & $1.95(0.90,4.22)$ & 0.09 & $2.11(0.88,5.07)$ & 0.09 & $2.34(1.05,5.21)$ & $0.04^{*}$ & $2.90(1.15,7.29)$ & $0.02^{*}$ \\
\hline
\end{tabular}

$B D$ bipolar disorder, $C l$ confidence interval, $E R$ emergency room, $H R$ hazard ratio, IP inpatient, MDD major depressive disorder, $T D$ tardive dyskinesia. ${ }^{*} P<0.05$ 


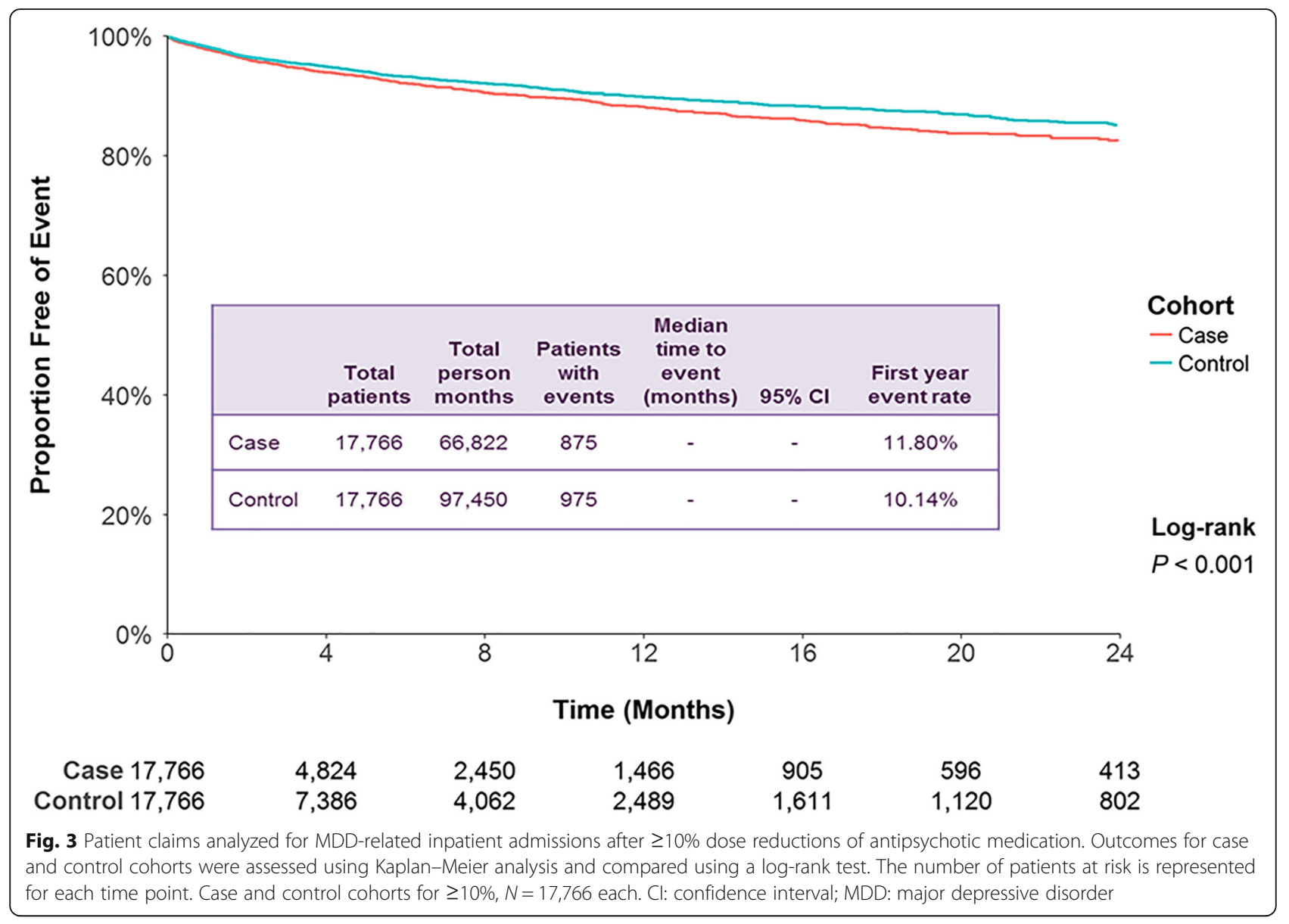

adjusted HR was 1.07 (95\% CI: 1.02, 1.11; $P<0.001$; Table 2). Results were similar for MDD cases with a $\geq 30 \%$ dose reduction vs. controls.

\section{TD claims}

The overall difference in TD claims between BD cases and controls was not significant: the adjusted HR was 1.45 (95\% CI: $0.75,2.82 ; P=0.27$ ) for the $\geq 10 \%$ dosereduction analysis and 1.83 (95\% CI: $0.87,3.88 ; P=0.11$ ) for the $\geq 30 \%$ dose-reduction analysis (Table 2 ).

When excluding patients with TD claims at baseline, the adjusted HR of a new TD claim was 1.95 (95\% CI: $0.90,4.22 ; P=0.09$ ) for the $\geq 10 \%$ dose-reduction analysis and $2.11(95 \% \mathrm{CI}: 0.88,5.07 ; P=0.09)$ for the $\geq 30 \%$ dose-reduction analysis (Table 2). Among patients with a pre-existing TD claim during the baseline period, the percentages of patients having at least one additional TD claim during the first year of the study period were compared between the dose-reduction cohort and the control cohort in both the $\geq 10 \%(16 / 18$ [88.9\%] vs $23 / 26$ [88.5\%], $P=0.97$ ) and the $\geq 30 \%$ dose-reduction analyses (14/15 [93.3\%] vs 20/23 [87.0\%]; $P=0.53)$.

MDD cases with dose reduction had a higher risk of TD claims vs. controls: the adjusted HR was 2.40 (95\%
CI: $1.19,4.83 ; P=0.01)$ for the $10 \%$ dose reduction analysis and 2.51 (95\% CI: 1.14, 5.52; $P=0.02$ ) for the $\geq 30 \%$ dose-reduction analysis (Table 2 ). When excluding patients with TD claims during baseline, the adjusted HR of a new TD claim was 2.34 (95\% CI: 1.05, 5.21; $P=$ 0.04 ) for the $\geq 10 \%$ dose-reduction analysis and 2.90 (95\% CI: $1.15,7.29 ; P=0.02$ ) for the $\geq 30 \%$ dose reduction analysis (Table 2). Among patients with a preexisting TD claim during the baseline period, the percentages of patients having at least one additional TD claim during the first year of the study period were compared between the dose-reduction cohort and the control cohort in both the $\geq 10 \%(16 / 19$ [84.2\%] vs $15 / 17$ [88.2\%], $P=0.73$ ) and the $\geq 30 \%$ dose-reduction analyses (12/13 [92.3\%] vs $14 / 16$ [87.5\%]; $P=0.67)$.

\section{Discussion}

While the use of antipsychotics in BD and MDD has become commonplace, there is a need for long-term evidence on the efficacy, safety, and necessity of maintenance antipsychotics in these populations. Although the accepted role of antipsychotics started during acute mania may be reflected in the greater number of patients with $\mathrm{BD}$ remaining on antipsychotics in the study 
sample, the necessity of antipsychotics in the maintenance treatment of BD and MDD is less well established [13]. The risk of TD and other side effects with prolonged treatment is substantial. This study used realworld claims data to compare the risk of both all-cause and mental health-related admissions and ER visits in patients with BD or MDD who had dose reductions with matched controls on stable oral dosages of antipsychotics. The results show that among patients with mood disorders, dose reductions resulted in small but statistically significant increases in inpatient admissions and ER visits, similar to previous findings among patients with schizophrenia [23].

As was observed in schizophrenia patients [23], differences in first-year hospital event rates were slight, especially between MDD cases and controls, but were statistically significant given the large sample size. The clinical meaningfulness of these differences should be considered by healthcare decision makers because even a $1 \%$ difference in event rates reflected an additional 240 patients using hospital services. Hospital re-admissions contribute to the economic burden for both patients and health systems [27]. An estimated 33.5 to $65.2 \%$ of the overall costs of treating patients with $\mathrm{BD}$ and approximately $38 \%$ of the cost of treating patients with MDD are attributable to patient hospitalization [28-30]. Comparing findings between mood disorder patients and schizophrenia patients in our previous analysis [23], BD patients were similar in disease-specific hospitalizations to patients with schizophrenia following dose reductions, but both of these disorders resulted in more hospitalizations than MDD patients, reflecting perhaps the greater heterogeneity in severity of the MDD subtype. TD claims were twice as common in schizophrenia which is consistent with recent reports $[8,10-12,18,23]$, but too few to reach definitive conclusions.

Analysis of the effects of dose reduction on claims for TD were only exploratory, descriptive and secondary to the primary outcome objective of hospitalizations. Moreover, interpretation of the relationship between dose reduction and TD is limited in this study by the shorter follow-up period in cases and the very low frequency of TD claims suggesting a high rate of false negative diagnoses [31]. In fact, the prevalence rate of TD reported in retrospective database studies like ours is significantly less than in prospective clinical trials of mood disorder patients $[11,12,23,32-34]$. These results clearly indicate that TD is seriously underreported in claims databases [34] and should be documented in a more systematic fashion. Nevertheless, our preliminary exploration found no evidence of fewer claims for TD after dose reduction. In fact, there were more claims in MDD patients following dose reduction, possibly representing withdrawal dyskinesias. Both MDD and BD patients with dose reduction also had higher rates of anticholinergic treatment; these drugs exacerbate symptoms of TD, which may then become apparent after antipsychotic dose reduction. In addition, it is possible that physicians proactively reduced the dose of antipsychotics due to some early signs of TD. Finally, apart from dose reduction, alternative strategies for treating TD may include antipsychotic discontinuation or switching to less-potent antipsychotics, or, more recently, to approved vesicular monoamine transporter-2 inhibitors (deutetrabenazine, valbenazine).

The strengths of this study include the use of a large claims data set based on real-world practice settings. Claims were analyzed from multiple states, with matched case and control groups. There are several limitations to the analyses. The reasons for antipsychotic dose reductions and whether dose reduction affected outcomes positively in other clinical domains were not assessed. For example, patients in the dose-reduction group had higher mean dosages in the pre-index period, as well as more cases of diabetes and use of anticholinergics, presumably for acute extrapyramidal symptoms, which may have prompted dose reductions [31]. Other changes in mood stabilizers or antidepressants could have influenced the results. A small number of cases and controls in both the BD (5.8\% vs. 5.6\%) and MDD (4.4\% vs $4.1 \%$ ) groups received a long-acting injectable antipsychotic in addition to their oral antipsychotic, but these differences were not significant (chi-square, $P$ value $>0.05$ ). Dose-reduction groups may have had more hospitalizations because they were more severely ill. However, patients with more severe disease would have been less likely to have doses reduced, and more severely ill patients were excluded if they received multiple oral antipsychotics during the baseline period or had recent increases in doses. Cases of BD and MDD were more likely to receive diagnoses of schizophrenia whereas other comorbid diagnoses (e.g., substance use disorder) that contribute to hospitalization were more common among controls. Both cohorts seemed to have patients with multiple psychiatric diagnoses as documented in coded medical records, which is typical of real-world studies and can reflect diagnostic uncertainties, psychiatric comorbidities, or the difficulty of determining which symptoms (e.g., psychotic episodes, depressed mood) are predominant. Outcome measures were also controlled for covariates in the Cox model that reflect severity.

Nonadherence to treatment is another factor that may increase the likelihood of hospitalization, but even if nonadherence contributed to hospitalizations, that would still be evidence suggesting untoward effects of dose reduction. High attrition during the study and the difference between cases and controls were due to the 
differences in outcomes. Kaplan-Meier analyses and Cox models were used to handle the attrition and censoring of patients; these statistical tools are designed to account for censored or truncated time-to-event data [35].

Finally, these results were limited to patients with mood disorders who received extended treatment with antipsychotics, and therefore are not generalizable to the much larger population of patients with mood disorders who respond to treatment without the need for antipsychotics.

\section{Conclusions}

These results showing small but statistically significant effects of antipsychotic dose reductions on hospitalization rates, especially among patients with $\mathrm{BD}$, reinforce similar findings in patients with schizophrenia [23]. The results did not support dose reduction for preventing or treating TD, but definitive conclusions could not be reached because of possible withdrawal dyskinesias, the limited duration of follow-up, use of anticholinergics, and underreporting of the diagnosis. Therefore, decisions on dose reduction of antipsychotics in patients with severe, psychotic, or recurrent mood disorders who require maintenance antipsychotic treatment should be carefully considered on an individualized basis. These results highlight the need for long-term studies of the necessity and safety of maintenance antipsychotic treatment in patients with mood disorders, and of alternative management strategies to address side effects that emerge during treatment.

\section{Supplementary information}

Supplementary information accompanies this paper at https://doi.org/10. 1186/s12888-020-02748-0.

Additional file 1. Diagnostic Codes for BD, MDD, and Other Psychiatric Conditions.

Additional file 2. Baseline Characteristics of Patients With $\geq 30 \%$ Antipsychotic Dose Reduction in the BD and MDD Groups.

Additional file 3. Dose Distributions Among Patients in the BD and MDD Groups During the $\leq 90$-day Stable Dose Period Prior to the Index Date for the 10 Most Commonly Used Antipsychotic Medications.

Additional file 4. Dose Reduction Percentiles for the 10 Most Commonly Used Antipsychotic Medications Among Patients in the BD and MDD Groups.

Additional file 5. Psychiatric Admission With $\geq 10 \%$ Antipsychotic Dose Reduction in the BD Group. Patient claims were analyzed for psychiatric admissions related to $\mathrm{BD}$ for $\geq 10 \%$ dose reductions of antipsychotic medication. Outcomes for case and control cohorts were assessed using Kaplan-Meier analysis and compared using a log-rank test. The number of patients at risk is represented for each time point. Case and control cohorts for $\geq 10 \%, N=23,992$ each. BD: bipolar disorder; Cl: confidence interval.

Additional file 6. All-Cause Inpatient Admissions Among Patients With $\geq 10 \%$ Antipsychotic Dose Reduction in the BD Group. Patient claims were analyzed for all-cause inpatient admissions related to BD for $\geq 10 \%$ dose reductions of antipsychotic medication. Outcomes for case and control cohorts were assessed using Kaplan-Meier analysis and compared using a log-rank test. The number of patients at risk is represented for each time point. Case and control cohorts for $\geq 10 \%, N=23,992$ each. BD: bipolar disorder; Cl: confidence interval; IP: inpatient.

Additional file 7. All-Cause Emergency Room Visits Among Patients With $\geq 10 \%$ Antipsychotic Dose Reduction in the BD Group. Patient claims were analyzed for all-cause emergency room admissions related to BD for $\geq 10 \%$ dose reductions of antipsychotic medication. Outcomes for case and control cohorts were assessed using Kaplan-Meier analysis and compared using a log-rank test. The number of patients at risk is represented for each time point. Case and control cohorts for $\geq 10 \%$, $N=23,992$ each. BD: bipolar disorder; Cl: confidence interval; ER: emergency room.

Additional file 8. Psychiatric Admission Among Patients With $\geq 10 \%$ Antipsychotic Dose Reduction in the MDD Group. Patient claims were analyzed for psychiatric admissions related to MDD for $\geq 10 \%$ dose reductions of antipsychotic medication. Outcomes for case and control cohorts were assessed using Kaplan-Meier analysis and compared using a log-rank test. The number of patients at risk is represented for each time point. Case and control cohorts for $\geq 10 \%, N=17,766$ each. Cl: confidence interval; MDD: major depressive disorder.

Additional file 9. All-Cause inpatient Admissions Among Patients With $\geq 10 \%$ Antipsychotic Dose Reduction in the MDD Group. Patient claims were analyzed for all-cause inpatient admissions related to MDD for $\geq 10 \%$ dose reductions of antipsychotic medication. Outcomes for case and control cohorts were assessed using Kaplan-Meier analysis and compared using a log-rank test. The number of patients at risk is represented for each time point. Case and control cohorts for $\geq 10 \%, N=17,766$ each. $\mathrm{Cl}$ : confidence interval; IP: inpatient; MDD: major depressive disorder.

Additional file 10. All-Cause ER Visits Among Patients With $\geq 10 \%$ Antipsychotic Dose Reduction in the MDD Group. Patient claims were analyzed for all-cause emergency room admissions related to MDD for $\geq 10 \%$ dose reductions of antipsychotic medication. Outcomes for case and control cohorts were assessed using Kaplan-Meier analysis and compared using a log-rank test. The number of patients at risk is represented for each time point. Case and control cohorts for $\geq 10 \%, N=17,766$ each. $\mathrm{Cl}$ : confidence interval; ER: emergency room; MDD: major depressive disorder.

\section{Abbreviations}

BD: Bipolar disorder; CCl: Charlson Comorbidity Index; Cl: Confidence interval; ER: Emergency room; FGA: First-generation antipsychotics; FFS: Fee-forservice; HR: Hazard ratio; HMO: Health maintenance organization; MDD: Major depressive disorder; SD: Standard deviation; SGA: Secondgeneration antipsychotics; TD: Tardive dyskinesia

\section{Acknowledgments}

Teva was involved in the design of the study and the collection, analysis, and interpretation of data. Analysis Group, Inc. was contracted by Teva to perform the analysis reported in this manuscript. Editorial assistance was provided by Dana Meyen, PhD (Chameleon Communications International) and Cherie Koch, PhD (MedErgy), with funding from Teva Pharmaceuticals.

\section{Authors' contributions}

All authors have read and approved the manuscript. SNC: Conception and design; analysis and interpretation of the data; drafting of the paper and revising it critically for intellectual content; read and approved the final version of the manuscript to be published. FM: Conception and design; analysis and interpretation of the data; drafting of the paper and revising it critically for intellectual content; read and approved the final version of the manuscript to be published. RA: Conception and design; analysis and interpretation of the data; drafting of the paper and revising it critically for intellectual content; read and approved the final version of the manuscript to be published. TS: Conception and design; analysis and interpretation of the data; drafting of the paper and revising it critically for intellectual content; read and approved the final version of the manuscript to be published. VA: Conception and design; analysis and interpretation of the data; drafting of the paper and revising it critically for intellectual content; read and approved the final version of the manuscript to be published. 
BC: Conception and design; analysis and interpretation of the data; drafting of the paper and revising it critically for intellectual content; read and approved the final version of the manuscript to be published

\section{Funding}

This study was funded by Teva Pharmaceuticals, Petach Tikva, Israel.

\section{Availability of data and materials}

Restrictions apply to the availability of these data, which were used under license for the current study, and are not publicly available. The data are available from the authors upon reasonable request and with permission of Analysis Group, Inc.

\section{Ethics approval and consent to participate}

The database complies with the privacy rules of the Health Insurance Portability and Accountability Act. This retrospective database analysis was granted an exemption by the New England Independent Review Board on August 31, 2017. As all pre-existing data within the database were anonymized, no informed consent was required.

\section{Consent for publication}

Not applicable.

\section{Competing interests}

SNC: Consultant for Teva Pharmaceuticals, Neurocrine Biosciences, Inc., Osmotica Pharmaceuticals, and DisperSol Technologies; received a research grant from Neurocrine Biosciences, Inc.

FM: Employee of Analysis Group, Inc.

RA: Employee of Analysis Group, Inc.

TS: Employee of Teva Branded Pharmaceutical Products R\&D, Inc.

VA: Former employee of Teva Pharmaceuticals.

BC: Employee of Teva Branded Pharmaceutical Products R\&D, Inc.

\section{Author details}

'Department of Psychiatry, Corporal Michael J. Crescenz VA Medical Center and the Perelman School of Medicine at the University of Pennsylvania, 3900 Woodland Avenue, Philadelphia, PA 19104, USA. ${ }^{2}$ Analysis Group, 111 Huntington Ave, Boston, MA 02199, USA. ${ }^{3}$ Teva Pharmaceuticals, 145 Brandywine Pkwy, West Chester, PA 19380, USA.

Received: 30 September 2019 Accepted: 19 June 2020

\section{Published online: 11 July 2020}

\section{References}

1. National Institute of Mental Health. Bipolar disorder [https://www.nimh.nih gov/health/statistics/bipolar-disorder.shtml]. Last update November 2017. Accessed 21 May 2020.

2. American Psychiatric Association. Depression [https://www.psychiatry.org/ patients-families/depression/what-is-depression]. Last update January 2017. Accessed 21 May 2020.

3. Fountoulakis KN, Yatham L, Grunze H, Vieta E, Young A, Blier P, Kasper S, Moeller HJ. The International College of Neuro-Psychopharmacology (CINP) treatment guidelines for bipolar disorder in adults (CINP-BD-2017), part 2: review, grading of the evidence, and a precise algorithm. Int J Neuropsychopharmacol. 2017;20(2):121-79.

4. Kemp DE. Managing the side effects associated with commonly used treatments for bipolar depression. J Affect Disord. 2014;169(Suppl 1):S34-44.

5. Mathews M, Gratz S, Adetunji B, George V, Mathews M, Basil B. Antipsychotic-induced movement disorders: evaluation and treatment. Psychiatry (Edgmont). 2005;2(3):36-41.

6. Correll CU, Detraux J, De Lepeleire J, De Hert M. Effects of antipsychotics, antidepressants and mood stabilizers on risk for physical diseases in people with schizophrenia, depression and bipolar disorder. World Psychiatry. 2015; 14(2):119-36.

7. Correll CU, Schenk EM. Tardive dyskinesia and new antipsychotics. Curr Opin Psychiatr. 2008;21(2):151-6.

8. Carbon M, Hsieh CH, Kane JM, Correll CU. Tardive dyskinesia prevalence in the period of second-generation antipsychotic use: a meta-analysis. J Clin Psychiatr. 2017;78(3):e264-78.

9. D'Abreu A, Akbar U, Friedman JH. Tardive dyskinesia: epidemiology. J Neurol Sci. 2018;389:17-20.
10. Caroff SN, Campbell EC. Drug-induced extrapyramidal syndromes: implications for contemporary practice. Psychiatr Clin North Am. 2016;39(3):391-411.

11. Keck PE Jr, McElroy SL, Strakowski SM, Soutullo CA. Antipsychotics in the treatment of mood disorders and risk of tardive dyskinesia. J Clin Psychiatry. 2000;61(Suppl 4):33-8.

12. Coplan J, Gugger JJ, Tasleem H. Tardive dyskinesia from atypical antipsychotic agents in patients with mood disorders in a clinical setting. J Affect Disord. 2013;150(3):868-71.

13. Cipriani A, Barbui C, Salanti G, Rendell J, Brown R, Stockton S, Purgato M, Spineli LM, Goodwin GM, Geddes JR. Comparative efficacy and acceptability of antimanic drugs in acute mania: a multiple-treatments meta-analysis. Lancet. 2011;378(9799):1306-15.

14. Ehret MJ, Levin GM. Long-term use of atypical antipsychotics in bipolar disorder. Pharmacotherapy. 2006;26(8):1134-47.

15. Butler M, Urosevic S, Desai P, Sponheim SR, Popp J, Nelson VA, Thao V, Sunderlin B. In: Treatment for Bipolar Disorder in Adults: A Systematic Review. Rockville (MD): Agency for Healthcare Research and Quality; 2018.

16. Boyce P, Irwin L, Morris G, Hamilton A, Mulder R, Malhi GS, Porter RJ. Long-acting injectable antipsychotics as maintenance treatments for bipolar disorder-a critical review of the evidence. Bipolar Disord. 2018;20(Suppl 2):25-36.

17. Parker GB, Graham RK, Tavella G. Is there consensus across international evidence-based guidelines for the management of bipolar disorder? Acta Psychiatr Scand. 2017;135(6):515-26.

18. Berman RM, Thase ME, Trivedi MH, Hazel JA, Marler SV, McQuade RD, Carson W, Baker RA, Marcus RN. Long-term safety and tolerability of openlabel aripiprazole augmentation of antidepressant therapy in major depressive disorder. Neuropsychiatr Dis Treat. 2011;7:303-12.

19. Glazer WM, Moore DC, Schooler NR, Brenner LM, Morgenstern H. Tardive dyskinesia. A discontinuation study. Arch Gen Psychiatry. 1984; 41(6):623-7.

20. Zutshi D, Cloud LJ, Factor SA. Tardive syndromes are rarely reversible after discontinuing dopamine receptor blocking agents: experience from a university-based movement disorder clinic. Tremor Other Hyperkinet Mov (N Y). 2014;4:266.

21. Caligiuri MP. Tardive dyskinesia: a task force report of the American Psychiatric Association. Psychiatr Serv. 1992:44(2):190.

22. Salem H, Pigott T, Zhang XY, Zeni CP, Teixeira AL. Antipsychotic-induced tardive dyskinesia: from biological basis to clinical management. Expert Rev Neurother. 2017;17(9):883-94.

23. Caroff SN, Mu F, Ayyagari R, Schilling T, Abler V, Carroll B. Hospital utilization rates following antipsychotic dose reductions: implications for tardive dyskinesia. BMC Psychiatry. 2018;18(1):306.

24. Bergman H, Rathbone J, Agarwal V, Soares-Weiser K. Antipsychotic reduction and/or cessation and antipsychotics as specific treatments for tardive dyskinesia. Cochrane Database Syst Rev. 2018;2:CD000459.

25. Soares-Weiser K, Fernandez HH. Tardive dyskinesia. Semin Neurol. 2007;27(2): 159-69.

26. Work Group on Major Depressive Disorder. Practice guideline for the treatment of patients with major depressive disorder 2010. [http:// psychiatryonline.org/pb/assets/raw/sitewide/practice_guidelines/guidelines/ mdd.pdf] Accessed 21 May 2020.

27. Bergeson JG, Kalsekar I, Jing Y, You M, Forbes RA, Hebden T. Medical care costs and hospitalization in patients with bipolar disorder treated with atypical antipsychotics. Am Health Drug Benefits. 2012;5(6):379-86.

28. Stender M, Bryant-Comstock L, Phillips S. Medical resource use among patients treated for bipolar disorder: a retrospective, cross-sectional, descriptive analysis. Clin Ther. 2002;24(10):1668-76.

29. Simon GE, Unutzer J. Health care utilization and costs among patients treated for bipolar disorder in an insured population. Psychiatr Serv. 1999; 50(10):1303-8

30. Greenberg PE, Fournier AA, Sisitsky T, Pike CT, Kessler RC. The economic burden of adults with major depressive disorder in the United States (2005 and 2010). J Clin Psychiatry. 2015;76(2):155-62.

31. Suzuki T, Uchida H, Tanaka KF, Tomita M, Tsunoda K, Nomura K, Takano H, Tanabe A, Watanabe K, Yagi G, et al. Reducing the dose of antipsychotic medications for those who had been treated with high-dose antipsychotic polypharmacy: an open study of dose reduction for chronic schizophrenia. Int Clin Psychopharmacol. 2003;18(6):323-9.

32. Bakker PR, de Groot IW, van Os J, van Harten PN. Long-stay psychiatric patients: a prospective study revealing persistent antipsychotic-induced movement disorder. PLoS One. 2011;6(10):e25588. 
33. van Harten PN, Matroos GE, Hoek HW, Kahn RS. The prevalence of tardive dystonia, tardive dyskinesia, parkinsonism and akathisia the curacao extrapyramidal syndromes study: I. Schizophr Res. 1996;19(2-3):195-203.

34. Cortese L, Jog M, McAuley TJ, Kotteda V, Costa G. Assessing and monitoring antipsychotic-induced movement disorders in hospitalized patients: a cautionary study. Can J Psychiatr. 2004;49(1):31-6.

35. Kleinbaum D, Klein M. Survival analysis: a self-learning text. 3rd ed. New York, NY: Springer; 2012.

\section{Publisher's Note}

Springer Nature remains neutral with regard to jurisdictional claims in published maps and institutional affiliations.

Ready to submit your research? Choose BMC and benefit from:

- fast, convenient online submission

- thorough peer review by experienced researchers in your field

- rapid publication on acceptance

- support for research data, including large and complex data types

- gold Open Access which fosters wider collaboration and increased citations

- maximum visibility for your research: over $100 \mathrm{M}$ website views per year

At $\mathrm{BMC}$, research is always in progress.

Learn more biomedcentral.com/submissions 